\author{
Anastasiya Nikolenko and Boris Melnykov
}

\title{
PHOTOCATALYTIC OXIDATION OF FORMALDEHYDE VAPOUR USING AMORPHOUS TITANIUM DIOXIDE
}

\author{
Ukrainian State University of the Chemical Engineering, \\ 8 Gagarin Av., 49005 Dniepropetrovsk, Ukraine \\ n_nikolenko@ukr.net
}

Received: September 18, 2009 /Revised: October 08, 2009 / Accepted: November 30, 2009

(C) Nikolenko A., Melnykov B., 2010

\begin{abstract}
The gas-phase photocatalytic oxidation of formaldehyde over illuminated amorphous titanium dioxide was investigated using a model flow reactor with the following experimental conditions: $0.1-0.5 \mathrm{l} / \mathrm{min}$ flow rate and an organic compound concentration range of 0.006$0.082 \mathrm{~mol} / \mathrm{m}^{3}$. Mathematical model of the process which includes two sequential stages: formation of formic acid and its subsequent oxidation to $\mathrm{CO}_{2}$ was offered. It was found that when the amount of $\mathrm{TiO}_{2}$ on carrying agent (anodized titanium) is $3.6 \mathrm{mg} / \mathrm{cm}^{2}$, the intensity of UV lamp is $18 \mathrm{~W}$ and the catalyst temperature is $293 \mathrm{~K}$, values of observed rate constants are equal to $6.5 \cdot 10^{-3} \mathrm{~s}^{-1}$ for the first stage and $1 \cdot 10^{-2} \mathrm{~s}^{-1}$ for the second stage of oxidation. The apparent activation energy of photocatalytic oxidation process of formaldehyde vapour for temperature interval $293-323 \mathrm{~K}$ is $20.2 \mathrm{~kJ} / \mathrm{mol}$.
\end{abstract}

Keywords: titanium dioxide, formaldehyde, photocatalytic oxidation process, model flow reactor.

\section{Introduction}

At present to purify gas emission the processes of absorption, adsorption, condensation, membrane separation as well as methods of thermal, chemical, catalytic and biochemical purification are used. It is possible to extend capabilities of the above methods of gas emission purification from toxic organic substances using the process of photocatalytic oxidation [1] which offers complete mineralization of organic compounds. Photocatalytic oxidation comprises the employment of semiconducting materials able to absorb light and generates radical particles with high oxidizing capacity. Gas-phase heterogeneous photocatalysis using $\mathrm{TiO}_{2}$ was first explored in 1990 [2]. It was reported about high levels of destruction of trichloroethylene when $\mathrm{TiO}_{2}$ was irradiated with ultraviolet light. Since then, series of other organic compounds photodegradation in the gas-phase has been extensively investigated [3, 4].
In this paper, the mechanism of photocatalytic oxidation of formaldehyde in a model flow reactor is studied. Formaldehyde is known to be a widespread organic air pollutant with relatively low maximum permissible concentration. For example, in the room air maximum permissible concentration of formaldehyde is $0.5 \mathrm{mg} / \mathrm{m}^{3}$. At present investigations into photocatalytic oxidation of formaldehyde were carried out by several authors [5-7]. The authors [5] show the possibility of rapid photodestruction of formaldehyde on dioxide titanium catalyst containing admixtures of carbon as an activator. Nanodispersible dioxide of titanium was used as a catalyst in [6]. It was concluded that the catalyst involved appears to be more active and promising for technical application. In work [7] photooxidation of formaldehyde in gas flow on titanium dioxide made in a form of a thin porous film on the surface of stainless steel gauze was studied. Unfortunately, the data submitted in [5-7] don't allow estimating efficiency of using photocatalysis for purifying industrial gas emissions.

The point is that designing of photoreactors needs thorough investigations into oxidation process at model or pilot plants of a flow type. Therefore, we seek to investigate kinetics of formaldehyde destruction in a model flow reactor. This data will be necessary for calculation of a reactor volume according to the initial concentration of formaldehyde and for determining conditions to reach complete transformation of formaldehyde to $\mathrm{CO}_{2}$.

\section{Experimental}

Investigations were carried out in a model plant, its main part being flow photoreactor. The UV lamp TLD18 W/08 class UVA, capacity $18 \mathrm{~W}$ and maximum emission band $370 \mathrm{~nm}$ was located axially in the reactor. The reactor length is $500 \mathrm{~mm}$ and reaction zone volume is $530 \mathrm{ml}$.

Amorphous titanium dioxide obtained from titanium hydroxide was used as a catalyst. Titanium hydroxide has 
been prepared by precipitation at $298 \mathrm{~K}$ and $\mathrm{pH}=11.0$ in a stirred reactor by mixing $\mathrm{TiOSO}_{4}$ and ammonium hydroxide so as to keep solution supersaturation constant throughout the precipitation process [8]: $\mathrm{TiO}^{2+}(\mathrm{aq})+2 \mathrm{OH}^{-}(\mathrm{aq}) \rightarrow$ $\mathrm{TiO}(\mathrm{OH})_{2}(\mathrm{~s})$. Then precipitate was filtered, extensively washed and calcined at $450 \mathrm{~K}$. The amorphous structure of the oxide was confirmed by X-ray diffraction analysis.

Aqueous suspension of obtained $\mathrm{TiO}_{2}$ powder was applied on the inner part of titanium pipe with the diameter of $50 \mathrm{~mm}$ and surface area $700 \mathrm{~cm}^{2}$. The precipitate obtained was dried at $383 \mathrm{~K}$. The amount of $\mathrm{TiO}_{2}$ on the carrier surface made up $3.6 \mathrm{mg} / \mathrm{cm}^{2}$.

To obtain a formaldehyde vapour the air current passed over $37 \%$ solution of formaldehyde with a certain rate $(0.1-0.5 \mathrm{l} / \mathrm{min})$. In a mixing flask the formaldehyde vapour was mixed with dried air and then entered the reactor. The temperature of the catalyst surface (293-400 K) was changed by means of cooling or heating the surface of the reactor case. When analyzing the gas mixture, the content of formaldehyde, formic acid and $\mathrm{CO}_{2}$ was determined. Formaldehyde content was determined by a photometric method employing colour reaction with phenylhydrazine. Formic acid was reduced in $\mathrm{HCl}$ medium by means of metallic magnesium with subsequent photometric determination of reduction product, i.e. formaldehyde. $\mathrm{CO}_{2}$ content was found by potentiometric back titration.

\section{Results and Discussion}

Before starting the investigation to obtain a stationary state of mass and heat exchange the reactor was in operating conditions for an hour. In previous studies it was determined that when $\mathrm{UV}$-irradiation or $\mathrm{TiO}_{2}$-catalyst was absent, the oxidation of formaldehyde did not proceed even at elevated temperature up to $320 \mathrm{~K}$. At the same time similar experiments at $400 \mathrm{~K}$ showed that as a result of auto-oxidation the concentration of formaldehyde vapours can slightly decrease (up to $5 \%$ in a studied time range). When exposed to the light of UV lamp photocatalyst showed natural reduction of final concentration of formaldehyde. After determining the composition of the gas mixture at various reactor loads it was found that with the decrease of the reaction mixture flow rate through the reactor concentration of formaldehyde reduces gradually, $\mathrm{CO}_{2}$ concentration gradually increases and the amount of formic acid first slightly increases and then reduces practically to zero (as to possibilities to use procedure of photometric determination). The example of graphic representation of relationship between concentration of all the determined components of the reaction mixture and reference time of photocatalytic oxidation reaction is shown in Fig.1. Reference time of the reaction was calculated as the relationship between the volume of reactor reaction zone and the value of its loading [8]. The value of reference time $\tau_{\mathrm{o}}$ at which the concentration of formaldehyde in the reactor accounted for its initial concentration measured in no UV radiation condition $\left(\Delta \tau=\tau-\tau_{0}\right)$ was taken as a starting point.

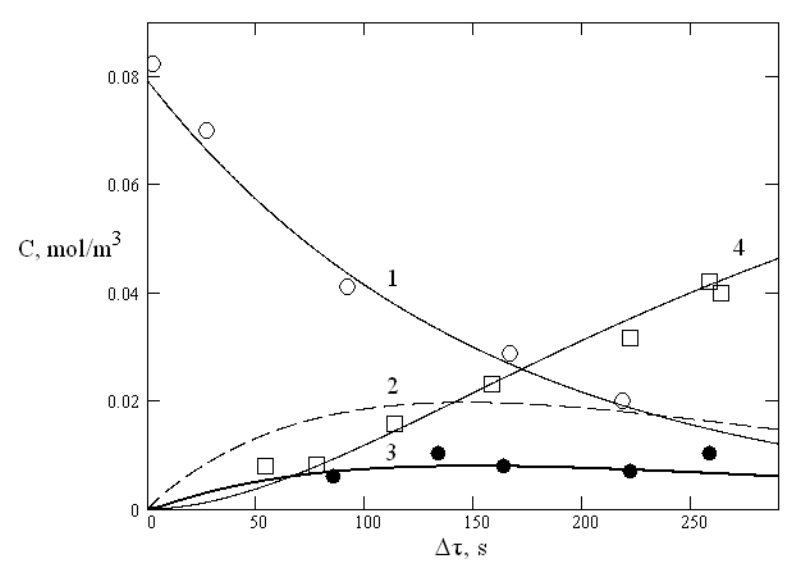

Fig.1. Dependence of formaldehyde concentration(1), formic acid $(2,3)$ and carbon dioxide (4) on conventional reaction time of photooxidation at catalyst temperature 293 K. (Dots show the experimental data and the curves are plotted on the basis of the mathematical model. The curve (2) depicts the calculation results of adsorbed formic acid)

Analysis of obtained kinetic data showed that the values of formaldehyde oxidation rate are linearized best of all in the coordinates of the first-order equation $\ln C-\Delta \tau)$. To explain the regularity determined we should take into account that the kinetics of higher-order reactions can be levelled to the kinetics of lower order under the conditions when one of the reaction components has rather high concentration. Also the first-order kinetics follows from the known equation for a heterogeneous chemical process:

$$
W_{A}^{\mathrm{HCOH}}=\frac{C_{\mathrm{HCOH}}^{0}}{\frac{1}{\beta_{1} S}+\frac{1}{k_{2} S C_{O x}}}=K_{A} C_{H \mathrm{COH}}^{0}
$$

where $W_{A}^{H C O H}$ is the observed rate of formaldehyde oxidation; $\mathrm{C}_{\mathrm{HCOH}}^{0}$ is the concentration of formaldehyde in a gas phase; $C_{O X}$ is the concentration of oxidizer active particles; $\beta$ is the mass exchange coefficient (relationship of a diffusion coefficient to the thickness of surface layer); $k_{2}$ is the constant of a reaction rate; $S$ is the catalyst surface.

The concentration of oxygen in the gas phase being hundred times as much as the amount of formaldehyde and generation of radical particles under the influence of 
UV radiation occurring constantly, we can assume that concentration of radical particles does not practically change (at least in comparison with the concentration of formaldehyde). Therefore the coefficient of proportionality $K_{A}$ can be assumed to be a stationary value, the values of and being invariable. Thus, photooxidation of formaldehyde under certain conditions can be described by the kinetic equation of the pseudofirst order.

As we know from [1], in absorbing light within the volume of $\mathrm{TiO}_{2}$ particle a free electron and electronic vacancy are formed. The electron and the vacancy give rise to the formation of radical particles which cause oxidation of organic substances:

$$
\begin{aligned}
& \mathrm{TiO}_{2}+h \mathrm{v} \rightarrow \mathrm{e}^{-}{ }_{(\mathrm{CB})}+\mathrm{h}^{+}{ }_{(\mathrm{VB})} \\
& \mathrm{h}^{+}{ }_{(\mathrm{VB})}+\mathrm{OH}^{-} \rightarrow \mathrm{OH}^{-}\left(\mathrm{or}^{+}{ }^{+}{ }_{(\mathrm{VB})}+\mathrm{H}_{2} \mathrm{O} \rightarrow \mathrm{OH}+\mathrm{H}^{+}\right) \\
& \mathrm{e}^{-}{ }_{(\mathrm{CB})}+\mathrm{O}_{2} \rightarrow \mathrm{O}_{2}^{--} \\
& \mathrm{O}_{2}^{--}+\mathrm{H}_{2} \mathrm{O} \leftrightarrow \mathrm{HO}_{2}+\mathrm{OH}^{-}
\end{aligned}
$$

where $\mathrm{e}_{(\mathrm{CB})}^{-}$is the electron of the conduction band, $\mathrm{h}^{+}{ }_{(\mathrm{VB})}$ is the vacancy of valence band.

In general, oxidation-reduction processes on the surface of the semiconductor catalyst involving formaldehyde, formic acid and oxygen can be expressed as:

$$
\begin{aligned}
& \mathrm{HCOH}+\mathrm{H}_{2} \mathrm{O}+2 \mathrm{~h}^{+} \rightarrow \mathrm{HCOOH}+2 \mathrm{H}^{+} \\
& \mathrm{HCOOH}+2 \mathrm{~h}^{+} \rightarrow \mathrm{CO}_{2}+2 \mathrm{H}^{+} \\
& \mathrm{O}_{2}+4 \mathrm{e}^{-}+4 \mathrm{H}^{+} \rightarrow \mathrm{H}_{2} \mathrm{O}
\end{aligned}
$$

According to these reactions the kinetic scheme of a photocatalytic formaldehyde transformation should include, as a minimum, two sequential stages: the formation of the formic acid from formaldehyde followed by its oxidation to $\mathrm{CO}_{2}$. It is known that kinetics of heterogeneous processes is well described by the Langmuir- Hinshelwood model. In approximation of this model it is supposed that surface concentrations of reactants are in equilibrium as to their volume concentrations, and the molecules in the absorbed layer appear to be very mobile. Before absorbed they undergo numerous collisions. Under this assumption the adsorption equilibrium is described by the Langmuir isotherm and the reaction rate is determined by the law of surface action (analogous with the law of mass action for chemical processes proceeding on the solid surface).

In approximation of the Langmuir-Hinshelwood model formaldehyde oxidation on the catalyst surface should be regarded as the sequence of adsorptiondesorption stages and chemical transformation:

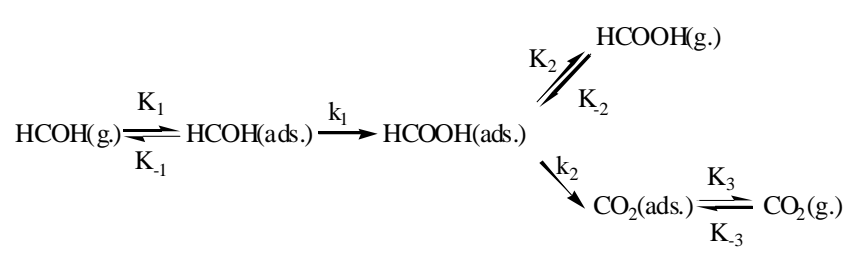

where $K_{1}$ and $K_{-1}$ are the constants of adsorption/desorption rate, $k_{1}$ is reaction constants, $g$ is the gas phase, ads are the adsorbed particles.

Since in fact we know only the volume but not surface concentrations of components in a gas phase, the kinetic equation was presented in the form of rate-toreagents concentration in a gas phase ratio. Therefore, to calculate rate constants a simplified model of the process was employed:

$$
\begin{aligned}
& \mathrm{HCOH}(\text { g. }) \stackrel{\mathrm{k}_{1}^{\prime}}{\longrightarrow} \mathrm{HCOOH} \text { (ads.) } \\
& \mathrm{k}_{2}^{\prime} \mathrm{CO}_{2} \text { (g.) }
\end{aligned}
$$

Mathematically such process is described by the following equations:

$$
\begin{aligned}
& \frac{d C_{H C O H}(g .)}{d \tau}=-k_{1}^{\prime} C_{H C O H(g .)} ;
\end{aligned}
$$

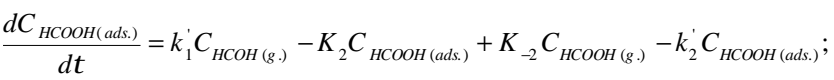

$$
\begin{aligned}
& \frac{d C_{\text {HСоОн(g.) }}}{d \tau}=K_{2} C_{\text {НСон (ads) }}-K_{-2} C_{\text {НСон }(\text { g. })} ; \\
& \frac{d C_{C_{2}(g)}}{d \tau}=k_{2}^{\prime} C_{H с O о H(a d s)} . \\
& \text { at } \tau=0: C_{\mathrm{HCOH}}=C_{0} \text {, } \\
& C_{\mathrm{HCOOH}(a d s .)}=C_{\mathrm{HCOOH}(\mathrm{g} .)}=C_{\mathrm{CO}_{2}(\text { ads. })}=0
\end{aligned}
$$

When calculating the rate constants of the process investigated the model of a plug-flow reactor was used. Possibilities of using the model involved was experimentally proved by determining distribution function of the reagent residence time in a reactor. On the basis of experimental studies of response curves an average conversion of formaldehyde was calculated, in the plug-flow reactor it accounted for $63.8 \%$ and in the model reactor it constituted $61.7 \%$. Closeness of the above values testifies that the process in the investigated model reactor can be considered as a plug flow [9].We also made calculations of Reynolds number for the gas flow in the model reactor. It was found that in the investigated range of rates Reynolds number does not exceed 44 units. Such low value of Re number shows that under chosen experimental conditions the gas mixture flow is laminar. The opportunity of disturbing the laminar gas flow at the reactor outlet and inlet may be neglected as the length of the reactor exceeds its effective diameter by 20 fold.

Within the plug-flow model the concentrations of every reactant were determined (see Fig. 1). Calculations of the curves $C \Delta \tau$ were carried out by Runge-Kutt method with a fixed pitch of integration [9]. On the basis of experimental data and mathematical model the values of 
constants $k_{1}$ and $k_{2}$ were calculated, the latter making up $6.5 \cdot 10^{-3} \mathrm{~s}^{-1}$ and $1 \cdot 10^{-2} \mathrm{~s}^{-1}$ respectively.

It was determined that the results of theoretical calculations agree with the experimental data provided the greater amount of formic acid is on the catalyst surface but not in the gas phase. This result is in accordance with the data of the authors [10], who found that when methanol undergoes photooxidation on $\mathrm{TiO}_{2}$ catalyst the formiates which are collected on the oxide surface are being quickly formed. Besides, it should be mentioned that the results obtained can also be explained by the occurring process of formic acid oxidation to carbon oxide (II). To test this hypothesis we carried out additional investigations to reveal the presence of $\mathrm{CO}$ in the reaction mixture. This was done by means of determining the total amount of carbon when passing the gas mixture (at $673 \mathrm{~K}$ ) through a pipe with an oxidized copper gauze which appears to be a catalyst of $\mathrm{CO}$ oxidation to $\mathrm{CO}_{2}$. The results of the experiments for the entire range of $\Delta \tau$ values showed no carbon oxide (II) in a gas outflow.

Thus, deviations of experimental data for the formic acid from calculated values should be explained by the increased adsorption on the catalyst surface. This conclusion is consistent with the literature data [11], which show that oxygencontaining organic substances may be selectively adsorbed on the oxides of titanium. In Fig. 1 the continuous line (curve 3 ) depicts the result of calculations for the amount of formic acid in the reactor gas phase with due account of its adsorption. The results of these calculations (given $K_{2} / K_{2}=10$ ) are in agreement with the experimental values obtained. Thus, the hypothesis of collecting formic acid molecules or ions on the catalyst surface explains the total set of experimental data.

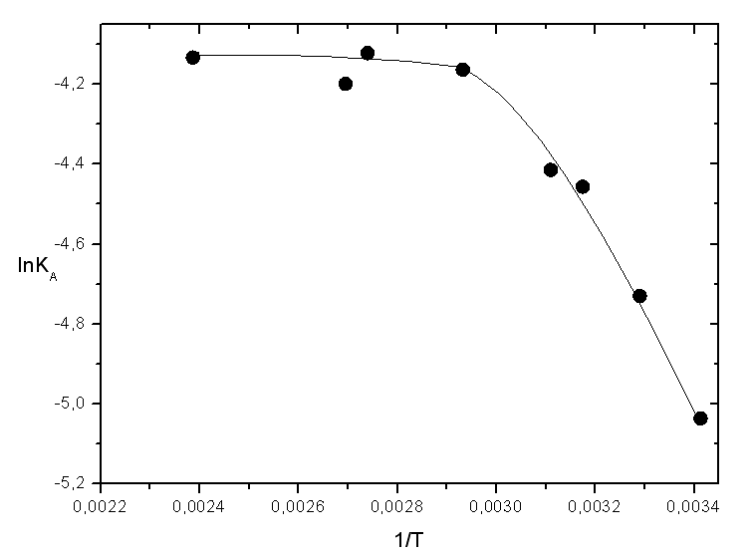

Fig. 2. Dependence between oxidation rate constants of formaldehyde and temperature of the catalyst in the coordinates of Arrhenius equation

The content of formaldehyde in the gas stream at different temperatures was determined for definition of limiting stage of the process rate. It was found that the obtained rate constants are well linearized on the coordinates of Arrhenius equation in a temperature range of 293-323 K with the apparent activation energy $20.2 \mathrm{~kJ} / \mathrm{mol}$ (see Fig. 2). Taking into account the low values of activation energies for radical reactions, it is possible to draw a conclusion that at room temperatures the oxidation process proceeds in a kinetic mode. As evident from Fig. 2, at temperatures higher $320 \mathrm{~K}$ the diffusive mode of oxidation process is observed.

\section{Conclusions}

On the basis of the investigations of formaldehyde destruction kinetics and collecting of formic acid and carbon (IV) in the gas medium of the reactor it was found that the rate of formaldehyde oxidation can be described by the kinetic equation of pseudofirst order. At modelling the photodestruction process by two sequential stages $\left(\mathrm{HCHO} \rightarrow \mathrm{HCOOH} \rightarrow \mathrm{CO}_{2}\right.$ ) it is necessary to assume that the formic acid is collected on the catalyst surface as the result of relatively strong adsorbability.

It was ascertained that under conditions of the flow reactor the observed rate constant of the formic acid photooxidation $\left(1 \cdot 10^{-2} \mathrm{~s}^{-1}\right)$ exceeds the corresponding value for formaldehyde $\left(6.5 \cdot 10^{-3} \mathrm{~s}^{-1}\right)$ only by 1.5 fold. Since this relationship of the values for rate constants of carboxylic acid and aldehyde oxidation may be caused by the difference both in diffusion coefficients and in rate constants of the chemical reactions themselves, it is impossible to explain differences in the rates of oxidation on the basis of the obtained experimental data.

The obtained results can be used for calculation of reactor volume according to initial concentration of formaldehyde and for determining conditions to reach complete transformation of formaldehyde to $\mathrm{CO}_{2}$. For example, under conditions of the model reactor at UV lamp power $18 \mathrm{~W}$ and $3.6 \mathrm{mg} / \mathrm{cm}^{2}$ of $\mathrm{TiO}_{2}$ on the surface being illuminated, practically complete purification of air containing $0.08 \mathrm{~mol} / \mathrm{m}^{3}$ of formaldehyde is achieved at $\tau \sim 450 \mathrm{~s}$.

\section{References}

[1] Carp O., Huisman C. and Reller A.: Progress in Solid State Chemistry, 2004, 32, 33.

[2] Dibble L. and Raupp G.: Catal. Lett., 1990, 4, 345.

[3] Alberici R. and Jardim W.: Appl. Catal. B, 1997, 14, 55.

[4] Wang S., Ang H. and Tade M.: Environ. Int., 2007, 33, 694.

[5] Huang B. and Saka S.: J. Wood Sci., 2003, 49, 79.

[6] Xiao X., Liao D. and Zhang H.: Front. Chem. Eng. China, 2007, 1(2), 178.

[7] Qing Y., Fen G., Ying X. et al.: Huanjing Kexue, 2005, 26, 35.

[8] Tsevis A., Spanos N., Koutsoukos P. et al.: J.Chem. Soc., Faraday Trans., 1998, 94, 295. 
[9] Emanuel N. and Knorre D.: Chemical Kinetics: Homogeneous Reactions. Wiley, New York 1973.

[10] Arana J., Dona-Rodriguez J., Garrida-Cabo C. et al.: Appl. Catal. B, 2004, 53, 221.

[11] Parfit G. and Rochester K. (Eds.): Adsorbziya iz Rastvorov na Poverhnostyah Tverdyh Tel. Mir, Moskwa 1986.

\section{ФОТОКАТАЛТТИЧНЕ ОКИСНЕННЯ ПАРІВ ФОРМАЛЬДЕГІДУ У ПРИСУТНОСТІ АМОРФНОГО ДІОКСИДУ ТИТАНУ}

Анотація. Вивчено газофазне фотокаталітичне окиснення формальдегіду на опроміненому аморфному діоксид $i$ титану, використовуючи модельний проточний реактор з наступними експериментальними умовами: 0.1-0.5 л·хв швидкості потокуі концентрацією органічних сполуку діапазоні 0.006-0.082 моль/м³. Запропонована математична модель прочесу, яка включає дві послідовні стадії: утворення з формальдегіду метанової кислоти і ї̈ наступне окиснення до $\mathrm{CO}_{2}$. Знайдено, щзо при кількості ТіО на поверхні носія

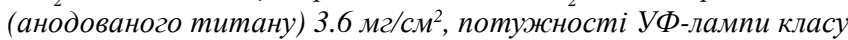
UVA 18 Bт і температурі каталізатору 293 К величини умовних констант швидкості дорівнюють $6.5 \cdot 10^{-3} c^{-1}$ для периої стадії $i$ $1 \cdot 10^{-2} c^{-1}$ для другої стадії окиснення. Ефективна енергія активачії процесу фотокаталітичного окиснення парів формальдегіду у температурному інтервалі 293-323 К становила 20.2 кДж/моль.

Ключові слова: діоксид титану, формальдегід, фотокаталітичний окисний процес, модельний проточний реактор. 